\title{
Bloodless Aortic and Coronary Artery Dissection: A Case Report
}

\author{
Filiz Eren ${ }^{1}$, Nursel Türkmen İnanir ${ }^{1,2}$, Bülent Eren ${ }^{*}$, Murat Serdar Gürses ${ }^{1}$, Recep Fedakar ${ }^{2}$, \\ Beatrice loan 4
}

\begin{abstract}
Aortic dissection is the most common catastrophic event affecting the aorta, which is characterized by complex clinical manifestations, and high missed and delayed diagnosis rate. Acute aortic dissection has the importance of medical emergency and is associated with a high mortality. The presented case was a 55-year-old man who was found as dead in the shed. In heart autopsy, a dissection $1 \mathrm{~cm}$ above the aortic valve surrounding full thickness and intact adventitia, hematoma making pressure on the descending branch of the left coronary artery $1 \mathrm{~cm}$ from the proximal one resulting from dissection and full- thickness dissection in the origin of the right coronary artery and intact adventitia were observed. We aimed to discuss this interesting aortic dissection case in the aspects of medico legal literature.
\end{abstract}

\section{Keywords}

autopsy; coronary disease; dissection

${ }^{1}$ Council of Forensic Medicine of Turkey, Bursa Morgue Department, Bursa, Turkey

${ }^{2}$ Forensic Medicine Department, Uludağ University of Medical Faculty, Bursa, Turkey

${ }^{3}$ Department of Forensic Medicine, Tokat Gaziosmanpaşa University School of Medicine, Tokat, Turkey

${ }^{4}$ Grigore T. Popa University of Medicine and Pharmacy, Institute of Legal Medicine, Iasi, Romania

${ }^{*}$ Corresponding author: drbulenteren@gmail.com

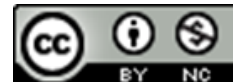

Copyright (C)Filiz Eren, Nursel Turkmen Inanir, Bulent Eren, Murat Serdar Gurses, Recep Fedakar, Beatrice Ioan, 2019

\section{Problem statement and analysis of the latest research}

Aortic dissection is the most common catastrophic event affecting the aorta, which is characterized by complex clinical manifestations, and high missed and delayed diagnosis rate [1]. Acute aortic dissection has the importance of medical emergency and is associated with a high mortality. Aortic dissection is estimated to occur at a rate of 0.5-4 cases per 100, 000 individuals per year [2, 3]. Two classical classification systems that are the Stanford and DeBakey classification systems are used for aortic dissection $[4,5]$.

The objective of the research was to discuss bloodless aortic dissection case where there was no blood or blood clot in the thorax or pericardia, $4 \times 3 \mathrm{~cm}$ in length ecchymosis on the front surface of the ascending aorta and hematoma were caused by dissection around the coronary artery.

\section{Case Report}

In our case, a 55-year-old man was found as dead in the shed. The death was evaluated as a suspicious by the public prosecutor, and the body was referred to our mortuary for an autopsy. In external autopsy: 55-year-old man's body was $178 \mathrm{~cm}$ in length, $85 \mathrm{~kg}$ in weight; there was cyanosis on the nail beds, earlobes and lips, oblique 11-cm opera- 


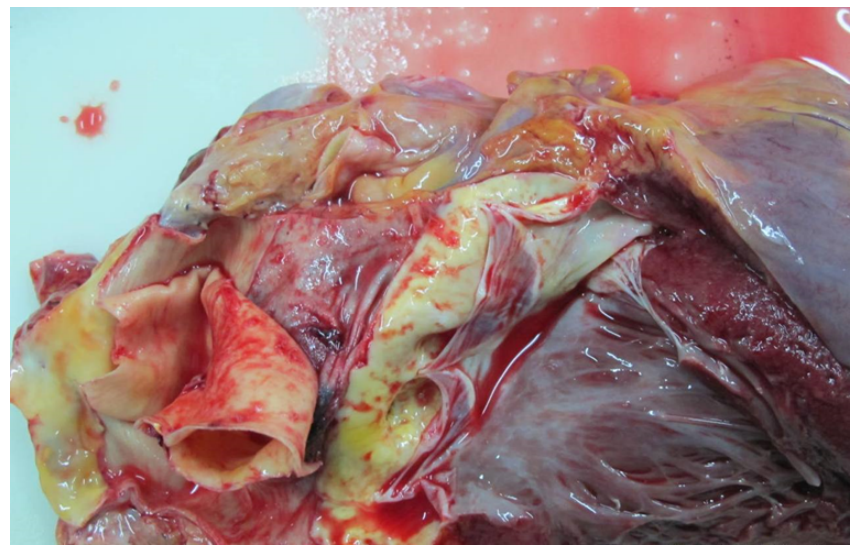

Figure 1. Ascending aorta: dissection $1 \mathrm{~cm}$ above the aortic valve surrounding full thickness and intact adventitia without hemorrhage into the dissected space.

tional scar on the right inguinal region; horizontal 2 -cm scar tissue on the dorsum of the nose. In internal autopsy: the heart weighted $507 \mathrm{~g}$; there were minimal atherosclerotic changes in the aorta; $4 \times 3$ $\mathrm{cm}$ in length ecchymosis on the front surface of the ascending aorta, dissection $1 \mathrm{~cm}$ above the aortic valve surrounding full thickness and intact adventitia (Fig. 1), hematoma making pressure on the descending branch of the left coronary artery $1 \mathrm{~cm}$ from the proximal one resulting from dissection and full- thickness dissection in the origin of the right coronary artery (all layers of the coronary artery) were detected (Fig. 2).

Microscopical examination of the lungs revealed edema, congestion, pigment-laden macrophages, and alveolar destruction of some walls. The weight of the lungs increased. Microscopical examination of the aorta revealed the calcification of the aorta wall, atherosclerotic changes. The toxicological investigations were completely negative. The cause of death was reported as aortic dissection.

\section{Discussion}

Acute aortic dissection has the importance of medical emergency and is a life-threatening disease with a high rate of mortality - an estimated $1 \%$ to $2 \%$ per hour for the first 48 hours [6]. The incidence of the disease increased two- to fourfold in the last

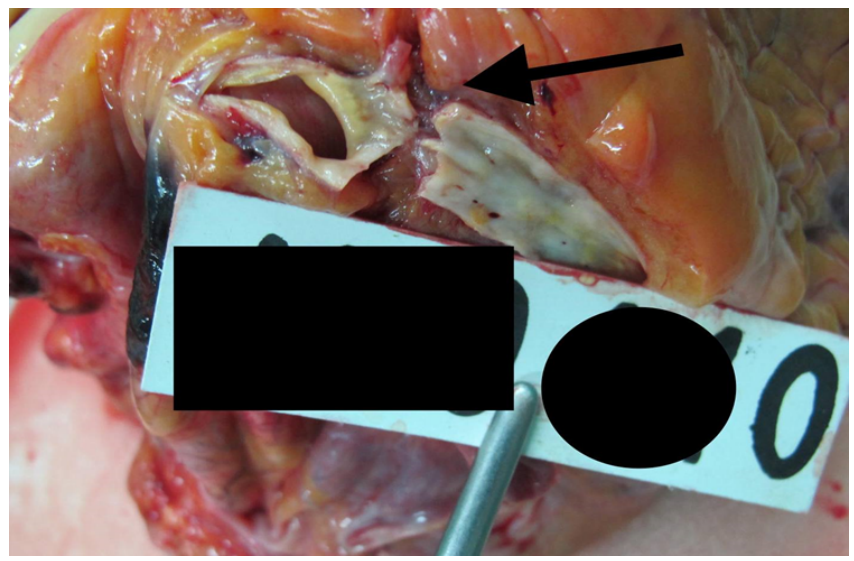

Figure 2. The arrow shows full-thickness dissection in the origin of the right coronary artery (all layers of coronary artery).

30 years [7]. Risk factors for aorta dissection include Ehlers-Danlos syndrome, Loeys-Dietz syndrome, familial thoracic aortic aneurysm syndrome, Shprintzen-Goldberg syndrome, hypertension, male sex, non-white race, bicuspid aortic valve, coarctation of the aorta, and the use of drugs including methamphetamine and cocaine $[8,9,10]$.

The Stanford classification and the DeBakey classification are used to separate aortic dissections into those that need surgical repair, and those that usually require only medical management. The DeBakey classification divides dissections into type I involving the ascending and descending aorta; type II involving the ascending aorta only; type III involving the descending aorta only [5]. The Stanford classification divides dissections into type A that affects the ascending aorta and the arch and type $\mathrm{B}$ that begins beyond the brachiocephalic vessels [4]. Svensson et al. reported a new classification - class 1: classic dissection with true and false lumen; class 2: intramural hematoma or hemorrhage; class 3: subtle dissection without hematoma; class 4: atherosclerotic penetrating ulcer; class 5: iatrogenic or traumatic dissection [11]. In our case, there was DeBakey type 1 and Stanford type A dissection. During autopsy, we revealed dissection 1 $\mathrm{cm}$ above the aortic valve surrounding full thickness (intima tear and aortic media tear) and intact adventitia; no blood was found in the thoracic cavity, pericardia and between the separated layers of 
dissection. Hematoma making pressure on the descending branch of the left coronary artery and fullthickness dissection in the all layer of the right coronary artery was detected as well.

Chest pain is the most common complaint following other complaints such as nausea, vomiting, dyspnea, syncope, and diaphoresis $[1,7,12]$. Before sudden cardiac arrest and death, the patients often complain of intense chest pain. The patients are often hypertensive, although they may be normotensive or hypotensive [1,12]. Clinical findings of aorta dissection are clinical symptoms that depend on the affected section of the vessel. The involvement of the great vessels may result in acute stroke syndrome. Depending on the extent of dissection and occlusion of the branches, end-organ ischaemia may also be present, including abdominal organ ischaemia, limb ischaemia, ischaemic or embolic stroke, paraplegia [7, 12]. Computed tomography, aortic angiography, transesophageal echocardiography, and magnetic resonance imaging are usually used to diagnose aortic dissection. However, aortic angiography is the traditional diagnostic method for the diagnosis of aortic dissection [7]. Cause of death in aortic dissection include cardiac tamponade, bleeding in the retroperitoneal space, visceral ischaemia, and myocardial infarction $[2,12,13]$. The therapy for aortic dissection is carried out using surgical and medical methods [1, 2, 7, 12]. A study reported that in case of aortic dissections, there were seen several histopathologic features, such as cystic medial necrosis, elastin fragmentation, fibrosis and medionecrosis in the aortic wall. According to the authors, cystic medial necrosis and elastin fragmentation may suggest a hereditary component and can help, especially considering the difficulty in a clinical diagnosis of Marfan syndrome [13]. Our case was aimed to discuss aortic and coronary artery dissection case where there was no blood or blood clot in the thorax or pericardia in medicolegal literature.

\section{References}

[1] Liu ZY, Zou YL, Chai BL, Zeng HS. Analysis of clinical features of painless aortic dissection.
J Huazhong Univ Sci Technolog Med Sci. 2014;34(4):582-585. DOI: https://doi. org/10.1007/s11596-014-1319-8

[PMid:25135731]

[2] Erbel R, Alfonso F, Boileau C et al. Task Force on Aortic Dissection, European Society of Cardiology. Diagnosis and management of aortic dissection. Eur Heart J. 2001;22(18):1642-1681. DOI: https:// doi.org/10.1053/euhj.2001.2782 [PMid:11511117]

[3] LeMaire SA, Russell L. Epidemiology of thoracic aortic dissection. Nat Rev Cardiol. 2011;8(2):103-113. DOI: https://doi. org/10.1038/nrcardio.2010.187

[PMid:21173794]

[4] Crawford ES, Svensson LG, Coselli JS et al. Surgical treatment of aneurysm and/or dissection of the ascending aorta, transverse aortic arch, and ascending aorta and transverse aortic arch. Factors influencing survival in 717 patients. J Thorac Cardiovasc Surg. 1989;98(5):659-674.

[5] DeBakey ME, McCollum CH, Crawford ES, Morris GC Jr, Howell J, Noon GP, Lawrie G. Dissection and dissecting aneurysms of the aorta: twenty-year follow-up of five hundred twenty-seven patients treated surgically. Surgery 1982;92(6):1118-1134.

[6] Hals G. Acute thoracic aortic dissection: current evaluation and management. Emerg Med Rep. 2000;21:1.

[7] Boie ET. Initial evaluation of chest pain. Emerg Med Clin North Am. 2005;23(4):937957. DOI: https://doi .org/10.1016/ j.emc.2005.07.007 [PMid:16199332]

[8] Salkin MS. Thoracic aortic dissection: avoiding failure to diagnose. ED Legal Letter 1997;8(11):107-118.

[9] Hasham SN, Willing MC, Guo DC et al. Mapping a locus for familial thoracic aortic 
aneurysms and dissections (TAAD2) to 3p2425. Circulation. 2003;107(25): 3184-3190.

DOI: https://doi.org/10.1161/ 01. CIR.0000078634.33124.95

[PMid:12821554]

[10] Weigang E, Chang XC, Munk-Schulenburg $S$ et al. Actual management of patients with familial ascending aneurysms and type-A aortic dissections. Thorac Cardiovasc Surg. 2007;55(1):19-23. DOI: https:// doi.org/10.1055/s-2006-924575

[PMid:17285469]

[11] Svensson LG, Labib SB, Eisenhauer AC, Butterly JR. Intimal tear without hematoma: an important variant of aortic dissection that can elude current imaging techniques. Circulation. 1999;99(10):1331-1336. DOI: https://doi.org/10.1161/01.CIR. 99.10.1331 [PMid:10077517]

[12] Hagan PG, Nienaber CA, Isselbacher EM et al. The international registry of acute aortic dissection (IRAD): new insights into an old disease. JAMA. 2000;283:897-903. DOI: https://doi.org/10.1001/jama. 283. . . 897 [PMid:10685714]

[13] Bode-Jänisch S, Schmidt A, Günther D et al. Aortic dissecting aneurysms-histopathological findings. Forensic Sci Int. 2012;214(13):13-17. DOI: https://doi.org/10 . 1016/j.forsciint.2011.07.006

[PMid:21794994]

Received: $2019-04-28$

Revised: 2019-05-07

Accepted: 2019-05-08 